\title{
Comparison of intraperitoneal bupivacaine, acetazolamide, and placebo on pain relief after laparoscopic cholecystectomy surgery: A clinical trial
}

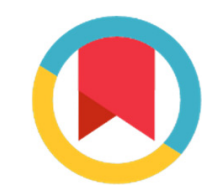

\author{
Poupak Rahimzadeh ${ }^{1}$, Seyed Hamid Reza Faiz ${ }^{2}$, Mostafa Hoseini ${ }^{2}$, Seyed Hamzeh Mousavie ${ }^{2}$, Farnad Imani ${ }^{1}$, \\ Ali Reza Negahi*2
}

Received: 1 Jan 2017

Published: 13 Nov 2018

\begin{abstract}
Background: Given the importance of patients' pain after laparoscopic surgeries, this study was conducted to compare the effectiveness of intraperitoneal bupivacaine, acetazolamide, and placebo on pain relief after laparoscopic cholecystectomy surgery.

Methods: Patients admitted to Rasool Akram hospital with physical status I or II, based on the American Society of Anesthesiologists (ASA) system, who were candidates for laparoscopic cholecystectomy surgery due to gallstones, were included in this study. Patients were divided into 3 groups (each group containing 20 patients) using block randomization with foursome blocks. Group 1 received bupivacaine, group 2 acetazolamide, and group 3 intravenous saline as placebo. After surgery, pain score was assessed by visual analogue scale, and shoulder pain and analgesic doses were also measured. The mentioned parameters were assessed at 1, 4, 8, 12, and 24 hours after surgery.

Results: In this study, 60 patients were included in 3 groups. The mean pain recorded (VAS) at 1, 4, and 8 hours after surgery was not significantly different between acetazolamide and bupivacaine groups, but their score was significantly lower than the placebo group $(\mathrm{p}<0.05)$. However, the score recorded at 12 and 24 hours after surgery was not significantly different between the 3 groups ( $p>0.05$ ). Mean of pain reliever (acetaminophen) injected to the patients when needed was not significantly different among the 3 intervention groups $(\mathrm{p}<0.05)$. The highest prevalence of shoulder pain $(70 \%)$ belonged to the placebo group and the lowest $(25 \%)$ to acetazolamide $(\mathrm{p}<0.05)$. Mean heart rate, systolic blood pressure, diastolic blood pressure, and the respiratory rate were not significantly different among intervention groups in $1,4,8,12$, and 24 hours after surgery $(\mathrm{p}>0.05)$.

Conclusion: According to the results, acetazolamide and bupivacaine injection reduced pain in early hours after laparoscopy. However, pain intensity was not different between intervention groups and the control group after 12 hours, so re-prescription seems to be appropriate at this time. Acetazolamide injection significantly reduces shoulder pains after surgery.
\end{abstract}

Keywords: Laparoscopy, Cholecystectomy, Pain, Acetazolamide, Bupivacaine

Conflicts of Interest: None declared

Funding: None

*This work has been published under CC BY-NC-SA 1.0 license.

Copyright $₫$ Iran University of Medical Sciences

Cite this article as: Rahimzadeh P, Faiz SHR, Hoseini M, Mousavie SH, Imani F, Negahi A. Comparison of intraperitoneal bupivacaine, acetazolamide, and placebo on pain relief after laparoscopic cholecystectomy surgery: A clinical trial. Med J Islam Repub Iran. 2018 (13 Nov);32:112. https://doi.org/10.14196/mjiri.32.112

\section{Introduction}

Pain, as an unpleasant sensory and emotional experience associated with tissue damage, is one of the most important causes of morbidity in patients after surgery. Many studies have shown that using anti-inflammatory drugs reduce complications after surgery, but the pain is not controlled

Corresponding author:DrAli Reza Negahi, negahi.ar@iums.ac.ir

1. Pain Research Center, Iran University of Medical Sciences, Tehran, Iran

2. Rasool Akram Hospital, Iran University of Medical Sciences, Tehran, Iran enough in most cases (3-1). Studies have shown that preventive control of pain weakens pain signals entered to the spinal cord, and it is more effective than when they are controlled after its creation (4). Laparoscopic cholecystectomy of selected treatment is symptomatic in most of the patients

$\uparrow$ What is "already known" in this topic:

Acetazolamide and bupivacaine injection reduced pain in laparoscopic cholecystectomy.

$\rightarrow$ What this article adds:

Acetazolamide injection significantly reduced shoulder pain after surgery. 
with cholecystitis (5). Pain after laparoscopic cholecystectomy is usually acute, with sharp nature that starts with surgical trauma and ends with the completion of the tissue restoration (8-6). While the intensity of this pain is lower than pain following open cholecystectomy, some patients experience significant discomforts in 24-72 hours after surgery, which can postpone the discharge time for patients $(6,7)$. The source of the pain after laparoscopic cholecystectomy surgery has several reasons. Pain arising from the incision site is a somatic pain, while pain arising from gallbladder bed has visceral nature, and shoulder pain is mainly followed by residual $\mathrm{CO} 2$ that stimulates the diaphragm. As a result, it seems that combined analgesic techniques can relieve post-operative pain in the best way (9). Abdominal pain usually occurs after surgery within the first 24 hours, and shoulder pain occurs in the second day after laparoscopy (10). Postoperative pain causes tachycardia, increased heart work following hypertension, nausea, vomiting, and ileus. As a result, pain relief and patient comfort during the initial hours following surgery is highly important, especially because the need to counter the pain may postpone the discharge time $(4,5,9)$. The adequacy of the control of postoperative pain is one of the most important determining factors for discharge time after the surgical process, which has a great impact on the patient's ability to continue normal daily activities of life (11). Intraoperative analgesics have been traditionally opioids. However, extensive use of opioids is associated with a variety of side effects during operation, such as respiratory depression, dizziness, and numbness, nausea, and vomiting after surgery, rash, urinary retention, ileus, and constipation, which may postpone discharge time (10).

Nowadays, a combination of non-opioid analgesics and opioid analgesics, such as local anesthetics, acetaminophen, and non-steroidal anti-inflammatory drugs, are popular methods to control postoperative pain. An ideal analgesic should be fast and long-acting and should have analgesic activity similar to or higher than such opioids as morphine. In addition, it should not have side effects (6).

Bupivacaine is a long-acting local anesthetic with a halflife of 2.5 to 3.5 hours, and it has been reported that it controls pain for 6 hours on average (4). Acetazolamide is a carbonic anhydrase inhibitor that prevents the formation of carbonic acid, which is a factor for abdominal and referral pains. Given the importance of pain after laparoscopic cholecystectomy surgery, we aimed to conduct a randomized clinical trial to compare the effectiveness of intraperitoneal bupivacaine, acetazolamide, and placebo on pain relief after laparoscopic cholecystectomy surgery to prevent prolonged hospitalization costs by determining the best method to reduce pain (12-14).

\section{Methods}

Patients who were candidates for laparoscopic cholecystectomy surgery due to gallstones and were admitted to Hazrat Rasool Akram hospital in 2015 were included in this study.

The registration ID in IRCT is IRCT2017032733159N1, and the code of Ethics Committee of IUMS is IR.IUMS.REC.13948623215562. According to the study of Upadya et al. (13), the sample size was calculated to be 66 patients using the following formula, and 79 patients were included in the final sample size considering $15 \%$ attrition:

$$
\mathrm{n}=\frac{\left(\mathrm{Z}_{(1-\alpha / 2)}+\mathrm{Z}_{(1-\beta)}\right)^{2}\left(\mathrm{sd}_{1}^{2}+\mathrm{sd}_{2}^{2}\right)}{\mathrm{d}^{2}}
$$

Inclusion criteria were as follow: Having physical status I or II of the ASA system (American Society of Anesthesiologists), age 20 to 60 years, and being a candidate for laparoscopic cholecystectomy surgery due to gallstones.

Exclusion criteria were as follow: Patient's consent to be included in the study, bile duct problems, acute cholecystitis, the need to continue laparoscopic surgery in the form of open surgery, lack of ability to understand and use visual analogue scale (VAS), experience of sensitivity to NSAIDs and local anesthetics, class III and IV of systems ASA, and patients with coledocolitiasis, and drain in situ.

After obtaining approval of the Ethics Committee of Iran University of Medical Sciences and obtaining written consent from patients, the patients were randomly assigned into 3 groups (each containing 20) using stratification and block randomization system with foursome blocks. Group 1(BUP) received intraperitoneal and local bupivacaine $0.5 \%$; the maximum dose was $2 \mathrm{mg}$ per kilogram; group 2 (AZL) received $0.5 \mathrm{mg}$ per $\mathrm{kg}$ acetazolamide and group 3 (P) intravenous saline as placebo.

Evaluations were performed on patients before anesthesia in the evening prior to the day of the surgery. The patients were trained to use visual analogue scale (VAS) and were asked to score their pain on a scale of 0 to 10 , with 0 indicating lack of pain and 10 the worst pain. Treatment before the surgery included $10 \mathrm{mg}$ of oral diazepam at night and $5 \mathrm{mg}$ in the morning of the surgery day for all patients. In the operating room, an IV line was embedded in the patient's non-dominant upper limb by gauge IV cannula 18 and the crystalloid infusion was started. To monitor the situation before surgery, blood pressure and pulse oximeter were measured using electrocardiogram (ECG), and blood pressure and heart rate were also assessed. All patients were anesthetized by propofol ( 2 to $2.5 \mathrm{mg}$ per $\mathrm{kg}$ ) until they had no verbal response. They also received vecuronium for intubation $(0.1 \mathrm{mg}$ per $\mathrm{kg})$. Maintenance was also done by $\mathrm{NO} 250 \%, \mathrm{O} 250 \%$, and $1 \mathrm{MAC}$ isoflurane. Ventilation was regulated so that while intra-abdominal pressure was between 10 and $12 \mathrm{mmHg}$, end-tidal $\mathrm{CO} 2$ would remain between 30 and $35 \mathrm{mmHg}$. Laparoscopy gas pressure was $12 \mathrm{mmHg}$ for all patients.

After removal of the gallbladder, $10 \mathrm{~mL}$ bupivacaine $0.5 \%$ was injected into the port location for group 1 (BUP) in the Trendelenburg position in the space right below the diaphragm ( $6 \mathrm{~mL}$ from wall of abdomen adjunct to middle line port and $4 \mathrm{~mL}$ from lateral section of port).Group 2 (AZL) received $0.5 \mathrm{mg} / \mathrm{kg}$ acetazolamide intravenously and group $3(\mathrm{P})$ intravenous saline as placebo. All patients were operated by 1 surgeon. After surgery, the pain of patients was assessed by the visual analogue scale, and shoulder pain and analgesic doses required were assessed. The mentioned parameters were assessed at 1, 4, 8, 12, and 24 hours after surgery by a person blind to the allocated 
groups. In the case of pain in patients, intravenous acetaminophen $500 \mathrm{mg}$ in $100 \mathrm{~mL}$ normal saline was prescribed in the form of infusion over 20 minutes and no drug was used. In the mentioned hours, blood pressure, heart rate, and respiratory rate per minute were assessed. Type of anesthesia and drugs received during the surgery were similar for all patients in the 3 groups. At the end, all information gathered in checklists was entered into statistical SPSS 22 software for analysis. To examine the normal distribution of data, the Kolmogorov-Smirnov test was used. In case of normal distribution of data, parametric tests were used, and non-parametric tests were used in case of non-normal distribution of data. Independent $t$ test or its non-parametric equivalent, Mann-Whitney U test, was used. In addition, paired $t$ test was used to compare the results before and after surgery. Also, to compare the ratio of changes among groups, variance analysis test on repeated measures test was used. To compare qualitative variables, chi-square test was utilized. In addition, confidence interval was used to better demonstrate the change in rates. In this study, $\mathrm{p}<0.05$ was considered significant.

\section{Results}

In this study, $55 \%$ of patients $(n=33)$ were male and $45 \%$ were female $(n=28)$. BMI and age distribution of patients in the 3 intervention groups were not significantly different (p>0.05) (Table 1). Consort flow chart was also drawn (Fig. 1). Mean pain score recorded based on VAS at 1, 4, and 8 hours after surgery was not significantly different between the 2 groups (AZL and BUP), but their score was

Table 1. Comparison of demographic and baseline characteristics of the patients in the 3 groups

\begin{tabular}{lccc}
\hline Variable & Group & Mean \pm SD & p \\
\hline Age (year) & BUP & $45.5 \pm 6.64$ & \\
& AZL & $44.3 \pm 5.31$ \\
& P & $47 \pm 5.64$ \\
BMI $(\mathrm{Kg} / \mathrm{m} 2)$ & BUP & $28.6 \pm 1.8$ & $28.3 \pm 1.9$ \\
& AZL & $27.2 \pm 1.9$ \\
\hline
\end{tabular}

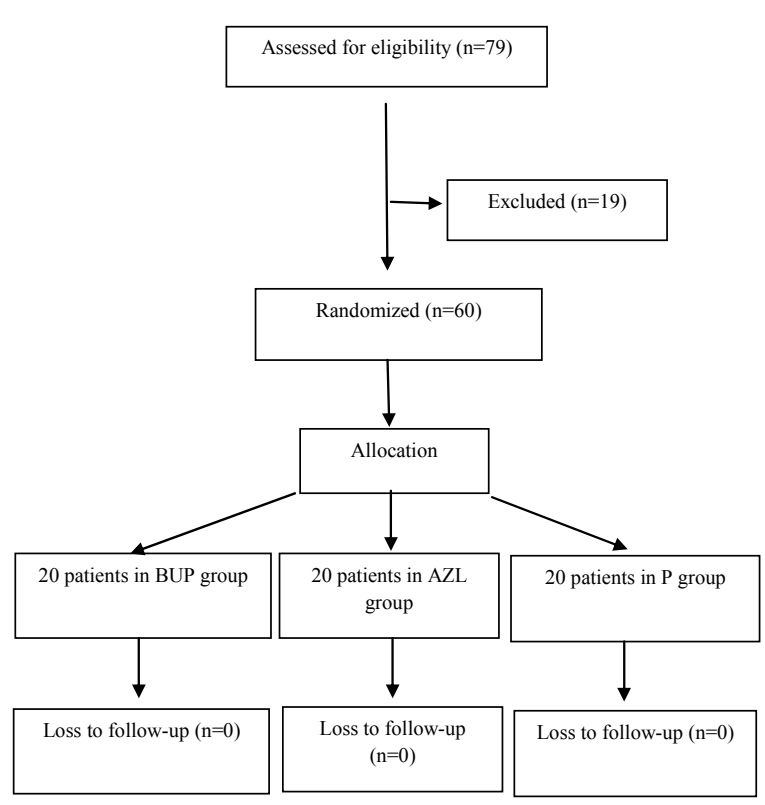

Fig. 1. Consort flow chart for follow-up of the patients

Table 2. Comparison of the pain score after the intervention in patients separately for each group

\begin{tabular}{|c|c|c|c|c|c|}
\hline Time & Group & Mean & Std. deviation & $\mathrm{F}$ & $\mathrm{p}$ \\
\hline \multirow{3}{*}{ VAS after 1 hour } & Bupivacaine & 3.13 & 0.69 & 39.36 & $<0.001$ \\
\hline & Acetazolamide & 3.30 & 0.41 & & \\
\hline & Placebo & 4.79 & 0.78 & & \\
\hline \multirow[t]{3}{*}{ VAS after 4 hours } & Bupivacaine & 2.78 & 0.80 & 35.27 & $<0.001$ \\
\hline & Acetazolamide & 2.00 & 0.11 & & \\
\hline & Placebo & 4.72 & 1.63 & & \\
\hline \multirow[t]{3}{*}{ VAS after 8 hours } & Bupivacaine & 2.80 & 0.68 & 23.39 & $<0.001$ \\
\hline & Acetazolamide & 2.62 & 0.44 & & \\
\hline & Placebo & 4.32 & 1.25 & & \\
\hline \multirow[t]{3}{*}{ VAS after 12 hours } & Bupivacaine & 4.32 & 0.91 & 8.16 & 0.001 \\
\hline & Acetazolamide & 3.22 & 0.57 & & \\
\hline & Placebo & 4.14 & 1.17 & & \\
\hline \multirow[t]{3}{*}{ VAS after 24 hours } & Bupivacaine & 3.46 & 1.63 & 7.57 & 0.001 \\
\hline & Acetazolamide & 2.22 & 0.63 & & \\
\hline & Placebo & 3.55 & 1.12 & & \\
\hline
\end{tabular}




\begin{tabular}{|c|c|c|c|c|c|}
\hline Dependent Variable & (I) Group & (J) Group & Mean Difference (I-J) & Std. error & $\mathrm{p}$ \\
\hline \multirow[t]{2}{*}{ VAS after 1 hour } & \multirow[t]{2}{*}{ Placebo } & Bupivacaine & 1.66 & 0.20 & $<0.001$ \\
\hline & & Acetazolamide & 1.49 & 0.20 & $<0.001$ \\
\hline \multirow[t]{3}{*}{ VAS after 4 hours } & Bupivacaine & Acetazolamide & 0.77 & 0.33 & 0.023 \\
\hline & \multirow[t]{2}{*}{ Placebo } & Bupivacaine & 1.94 & 0.33 & $<0.001$ \\
\hline & & Acetazolamide & 2.71 & 0.33 & $<0.001$ \\
\hline \multirow[t]{2}{*}{ VAS after 8 hours } & \multirow[t]{2}{*}{ Placebo } & Bupivacaine & 1.52 & 0.27 & $<0.001$ \\
\hline & & Acetazolamide & 1.70 & 0.27 & $<0.001$ \\
\hline \multirow[t]{2}{*}{ VAS after 12 hours } & Bupivacaine & Acetazolamide & 1.09 & 0.29 & $<0.001$ \\
\hline & Placebo & Acetazolamide & 0.92 & 0.29 & 0.003 \\
\hline \multirow[t]{2}{*}{ VAS after 24 hours } & Bupivacaine & Acetazolamide & 1.23 & 0.38 & 0.002 \\
\hline & Placebo & Acetazolamide & 1.32 & 0.38 & $<0.001$ \\
\hline
\end{tabular}

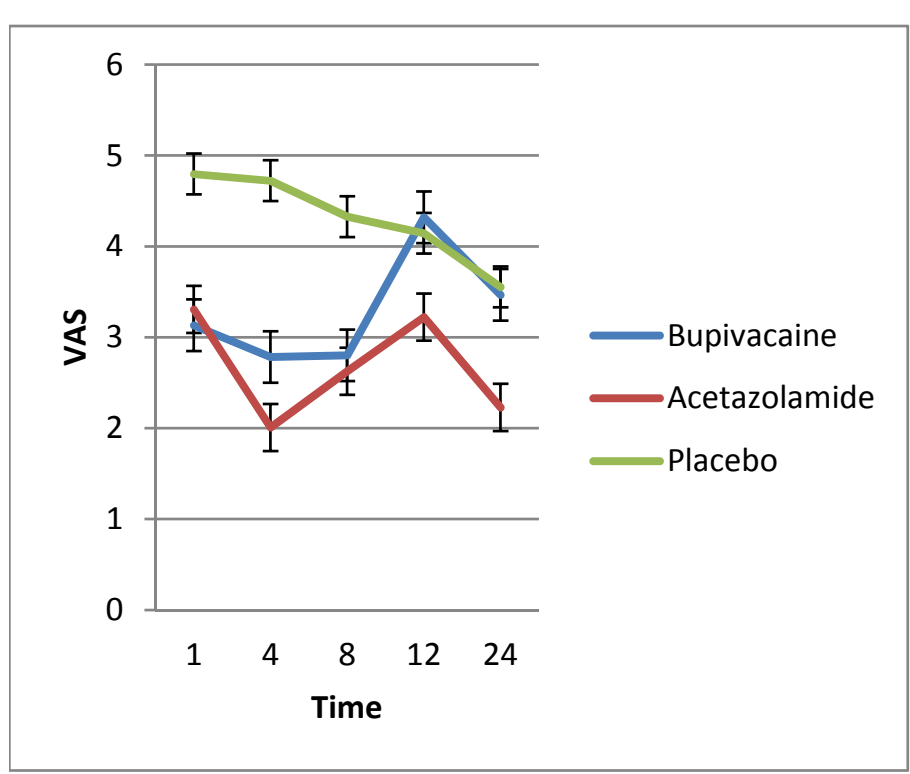

Fig. 2. Comparing the changes in the mean pain score at different hours after surgery among the 3 groups

significantly lower than that of P group $(\mathrm{p}<0.05)$ (Table 2$)$. Table 3 demonstrates the compare-wise analysis (post hoc) for the 3 groups. However, the pain score recorded at 12 and 24 hours after surgery was not significantly different between the 3 intervention groups ( $p>0.05$ ) (Fig. 2). The mean of pain relief dose (acetaminophen) injected into the patient when needed was calculated and found to be not significantly different among 3 groups $(\mathrm{p}<0.05)$. After the surgery, $5(25 \%), 12(60 \%)$, and $14(70 \%)$ patients had shoulder pain in the AZL, BUP, and P groups, respectively. In this regard, the prevalence of shoulder pain after the surgery in the AZL group was significantly lower than the other 2 groups $(\mathrm{p}=0.011)$. The mean heart rate, systolic blood pressure, diastolic blood pressure, and respiratory rate of patients among intervention groups were not significantly different at $1,4,8,12$, and 24 hours after surgery $(\mathrm{p}>0.05)$.

\section{Discussion}

Several studies have been conducted to date in the field of pain relief after surgery. In a study conducted by Shivhare, they stated that slowly injecting ropivacaine is effective in reducing abdominal pain in the early hours after laparoscopic cholecystectomy surgery rather than placebo (14). However, according to the results obtained in our study, the main pain score was observed at 8 hours after the initial surgery and was not significantly different in the 2 groups of BUP and AZL, but the mean pain score of the 2 mentioned group was significantly less than P group. Still, mean pain score recorded at the times, excluding 8 hours after surgery, was not significantly different between the 3 intervention groups. This result was expected considering the duration of the effects of the drugs used. The duration of the effect of acetazolamide is 8-12 hours and the duration of the pain reduction is also in the same time range. In addition, duration of the effect of bupivacaine was found to be in the same range (15-17).

Additionally, by reducing the doses of these drugs in the blood, the mean pain score in these 2 groups increased 8 to 12 hours after the surgery and reached to placebo group. In hours between 12 and 24, all groups experienced a decline in pain as expected. Although pain intensity in $\mathrm{P}$ group was significantly more than that in the other 2 groups in the early hours, it declined after 24 hours. To our knowledge, no study has been conducted to simultaneously compare these drug regimens in patients undergoing cholecystectomy surgery. Results obtained by Alleyassin, who compared the pain scores between lidocaine and bupivacaine injected intraperitoneally, showed that bupivacaine is more effective in reducing pain after surgery (18). Another study, which was conducted in 2015 to compare intraperitoneal bupivacaine and intravenous paracetamol on pain reduction after laparoscopic cholecystectomy surgery, indicated that intraperitoneal bupivacaine $0.5 \%$ reduces the pain severity of incision site, visceral pain, and shoulder pain in the early hours after surgery (13). Woehlck et al., who investigated 
the effect of acetazolamide on reduction of pain after laparoscopic cholecystectomy on 38 patients, stated that acetazolamide was effective in reducing referral pain after the surgery, but it had no significant impact on surgical incision site pain (17). This study was in line with our study in reducing referral pain after taking acetazolamide. However, using acetazolamide in our study, especially in the early hours after the surgery, reduced the general pain score. In contrast to our findings, another study compared the oral acetazolamide before surgery and intraperitoneal injection of normal saline on pain score after laparoscopic cholecystectomy and found that intraperitoneal injection of normal saline was more effective in reducing visceral pain after laparoscopic cholecystectomy surgery, while its impact on shoulder pain was equal to acetazolamide effect (19). In addition, doses used in these 2 studies were equal, $5 \mathrm{mg} / \mathrm{kg}$ of acetazolamide. Patients mainly experience 2 types of pain following laparoscopic cholecystectomy surgery. One is experienced in the incision areas of trocar and the surgical site, and the other type is pain of the right shoulder due to combination reaction of $\mathrm{CO} 2$ and fluid available in the surgical site and creation of carbonic acid. Due to inflammation, carbonic acid causes diaphragm stimulation and the pain will be referred to the right shoulder. In previous studies, pain in all patients who underwent laparoscopic cholecystectomy surgery was examined using $\mathrm{CO} 2$ injection in peritoneum; and it was shown that the use of acetazolamide injection reduces referral pain, but it has no effect on pain in the incision and surgical site (20). It is assumed that drugs that reduce the production of hydrogen ion can contribute to reduction of pain arising from laparoscopic surgery. One of these drugs is acetazolamide. This drug, by inhibiting carbonic anhydrase enzyme, causes reduction in creation of hydrogen ions and bicarbonate ions from carbon dioxide and water and reduces access to these ions to move actively into the body secretions $(8,21-23)$. According to our findings, the pain referred to the shoulder in AZL group was significantly lower than the other 2 groups. The duration of the effect of acetazolamide on reduction of referral pain was similar to the drug half-life $(15,16)$.

To reduce pain longer, instead of a single dose, multiple doses of acetazolamide can be used. However, studies suggest that the treatment of referral pain is needed only in short time after the surgery and $\mathrm{CO} 2$ would be absorbed after couple of hours $(16,23)$. This indicates that a single dose of acetazolamide could be efficient for this purpose. By reducing the acidity of fluid under diaphragm, acetazolamide reduces the pain referred to the shoulder (24-26). Previous studies have shown that one of the mechanisms of pain creation is tissue acidosis. Acetazolamide, either oral or IV, is a potent inhibitor of the carbonic anhydrase enzyme, which one of its known effects is tissue metabolic acidosis (27-29). In Woehlck study, acetazolamide led to a significant reduction in referral pains, which was in favor of our findings (17).

Moazeni stated that oral acetazolamide reduces the pain referred to the right shoulder, perhaps by reducing the acidity of abdominal fluid. However, they stated that due to creation of tissue acidosis, which is one of the side effects of this drug, acidosis simultaneously increases abdominal pain in the surgical site and the right shoulder pain due to diaphragm stimulation after the surgery (20).

In our study, despite the difference in pain at early hours among the intervention groups, the mean pain reliever received was not significantly different among the groups. Additionally, in our study, the mean heart rate, systolic blood pressure, diastolic blood pressure, and respiratory rate of patients in the intervention group were monitored at consecutive hours after surgery, and no significant difference was observed. Thus, it seems that the use of these pain-suppressing drugs had led to a significant pain relief in patients while having no significant side effects. Therefore, these drugs can be used to reduce pain in patients who had laparoscopic cholecystectomy surgery. Some of the shortcomings and limitations of this study included lack of attention to the impact of duration of surgery and the amount of intra-abdominal pressure and $\mathrm{PH}$ within the abdomen of the patients. Since acetazolamide causes alkaline diuresis, it would be safer to perform $\mathrm{ABG}$ in patients who underwent laparoscopic surgery. It is recommended that other studies take into account the above-mentioned factors.

\section{Conclusion}

According to the results obtained in this study, injection of acetazolamide and bupivacaine reduces pain in early hours after laparoscopy. However, the amount of pain will not be different from the control group after 12 hours. Therefore, acetazolamide or bupivacaine re-prescription seems to be appropriate at this time. Acetazolamide injection significantly reduces pains referred to the shoulder after surgery.

\section{Acknowledgments}

The authors wish to thank Rasool Akram Hospital Clinical Research Development Center, Iran University of Medical Sciences.

\section{Conflict of Interests}

The authors declare that they have no competing interests.

\section{References}

1. Arroyo-Novoa CM, Figueroa-Ramos MI, Miaskowski C, Padilla G, Paul SM, Rodríguez-Ortiz P, et al. Efficacy of small doses of ketamine with morphine to decrease procedural pain responses during open wound care. Clin J Pain. 2011;27(7):561-566.

2. Benitez-Rosario MA, Salinas-Martin A, Gonzalez-Guillermo T, Feria M. A strategy for conversion from subcutaneous to oral ketamine in cancer pain patients: Effect of a 1:1 ratio. J Pain Symptom Manage. 2011;41(6):1098-1105.

3. Kamalipour H, Ahmadi S. Local infiltration of lidocaine versus lidocaineiontophoresis in pain relief during radial artery cannulation for open heart surgery. Iran Red Cresc Med J. 2007;9(3):133-38.

4. Sedighinejad A, Haghighi M, Naderi Nabi B, Rahimzadeh P, Mirbolook A, Mardani-Kivi M, et al. Magnesium sulfate and sufentanil for patient-controlled analgesia in orthopedic surgery. Anesth Pain Med. 2014 Feb 28;4(1):e11334

5. Goushe MR, Nesioonpour SH, Javaherforoosh F, Akhondzadeh $\mathrm{R}$, Sahafi SA, Alizadeh Z. Intra venous paracetamol for postoperative analgesia in laparascopic cholecystectomy. Anesthesiol Pain Med. 2013;3(1):214-8

6. Rawal N. Analgesia for day-case surgery. Br J Anaesth. 2001;87:73- 
87.

7. Ready LB, Oden R, Chadwick HS, Benedetti C, Rooke GA, Caplan R, et al. Development of an anesthesiology-based postoperative pain management service. Anesthesiology. 1988;68:100-6.

8. Joshi GP, White PF. Postoperative pain management: Day surgery. In: Rowbotham DJ, McIntyre P, editors. Clinical Pain Management Acute Pain. London: Arnold; 2003. pp. 329-40.

9. Alam MS, Hoque HW, Saifullah M, Ali MO. Port site and intraperitoneal infiltration of local anesthetics in reduction of post-operative pain after laparoscopic cholecystectomy. Med Today. 2009;22:24-8.

10. Lepner U, Goroshina J, Samarutel J. Postoprative pain relief after laparascopic cholecystectomy: A randomized prospective double-blind clinical trial. Scand J Surg. 2003;92:121-124.

11. Gayatri P. Post-operative pain services. Indian J Anesth. 2005;49:179.

12. Harvey JW, Otterson M, Yun H, Connolly LA, Eastwood D, Colpaert $\mathrm{K}$. Acetazolamide reduces referred postoperative pain after laparoscopic surgery with carbon dioxide insufflation. Anesthesiology. 2003;99:924-8.

13. Upadya M, Pushpavathi SH, Seetharam K. Comparison of intraperitoneal bupivacaine and intravenous paracetamol for postoperative pain relief after laparoscopic cholecystectomy. Anesth Essays Res. 2015; 9(1):39-43.

14. Shivhare P, Dugg P, Singh H, Mittal S, Kumar A, Munghate A. A Prospective Randomized Trial to Study the Effect of Intraperitoneal Instillation of Ropivacaine in Postoperative Pain Reduction in Laparoscopic Cholecystectomy. J Minim Invasive Surg Sci. 2014 November; 3(4): e18009.

15. Lyall DA. Unexpected control of a patient's refractory epilepsy when treating glaucoma with acetazolamide. Can J Ophthalmol. 2008;43(3):377.

16. Millitz K, Moote DJ, Sparrow RK, Girotti MJ, Holliday RL, McLarty TD. Pneumoperitoneum after laparoscopic cholecystectomy: frequency and duration as seen on upright chest radiographs. AJR Am J Roentgenol. 1994;163(4): 837-9.

17. Woehlck HJ, Otterson M, Yun H, Connolly LA, Eastwood D, Colpaert K. Acetazolamide reduces referred postoperative pain after laparoscopic surgery with carbon dioxide insufflation. Anesthesiology. 2003 Oct;99(4):924-8.

18. Alleyassin A, Khademi A, Shoeibi G, Khalili B. [Intraperitoneal injection of Bupivacaine and Lidocaine in reducing postoperative pain in gynecologic laparoscopic surgeries: a comparative study]. Tehran Univ Med J. 2007;65(4):19-23. [Persian]

19. Indu B, Nidhi B, Pragnyadipta M, Ganga Ram V, Lileshwar K. Comparison of Preoperative Oral Acetazolamide and Intraperitoneal Normal Saline Irrigation for Reduction of Postoperative Pain After Laparoscopic Cholecystectomy. J Laparoendosc Adv Surg Techniq. April 2015;25(4): 285-290.

20. Moazeni-Bistgani M, Mohammad Ali-Beigi F, Shahrjerdi S. Assessment of oral acetazolamide on postoperative pain after laparoscopic cholecystectomy. J Shahrekord Uni Med Sci. 2010;12(2):21-26.

21. Faiz HR, Rahimzadeh P, Visnjevac O, Behzadi B, Ghodraty MR, Nader ND. Intravenous acetaminophen is superior to ketamine for postoperative pain after abdominal hysterectomy: results of a prospective, randomized, double-blind, multicenter clinical trial. J Pain Res. 2014 Jan 17;7:65-70

22. Takeda K, Nakamoto M, Yasunaga C, Nishihara G, Matsuo K, Urabe $\mathrm{M}$, et al. Acute hemorrhagic gastritis associated with acetazolamide intoxication in a patient with chronic renal failure. Clin Nephrol. 1997;48(4):266-8.

23. Schwenk MH, Blaustein DA, Wagner JD. The pharmacokinetics of acetazolamide during CAPD. Adv Perit Dial. 1994;10:44-6.

24. Rudston-Brown BC, MacLennan D, Warriner CB, Phang PT. Effect of subcutaneous carbon dioxide insufflation on arterial $\mathrm{pCO}_{2}$. Am J Surg. 1996;171(5):460-3.

25. Woehlck HJ, Otterson M, Yun H, Connolly LA, Eastwood D, Colpaert K. Acetazolamide reduces referred postoperative pain after laparoscopic surgery with carbon dioxide insufflation. Anesthesiology. 2003 Oct;99(4):924-8.

26. Hanly EJ, Mendoza-Sagaon M, Murata K, Hardacre JM, De Maio A, Talamini MA. $\mathrm{CO}_{2}$ pneumoperitoneum modifies the inflammatory response to sepsis. Ann Surg. 2003 Mar;237(3):343-50.

27. Safari S, Rahimzadeh P, Haghighi M. Local infiltration anesthesia: does it really work? Ann Transl Med. 2015 Oct;3(18):275.
28. Rahimzadeh P, Imani F, Faiz SH, Nikoubakht N, Sayarifard A. Effec of intravenous methylprednisolone on pain after intertrochanteric femoral fracture surgery. J Clin Diagn Res. 2014 Apr;8(4):GC01-4.

29. Sun YJ, Chen Y, Pang C, Wu N, Li J. Acetazolamide attenuates chemical-stimulated but not thermal-stimulated acute pain in mice. Acta Pharmacol Sin. 2014 Jan;35(1):41-7. 